\title{
Dr Livingstone, I presume?
}

T t seems to me that physicians are much more likely than the members of other 1 professions to take on exploration or selfless service in distant parts of the world.

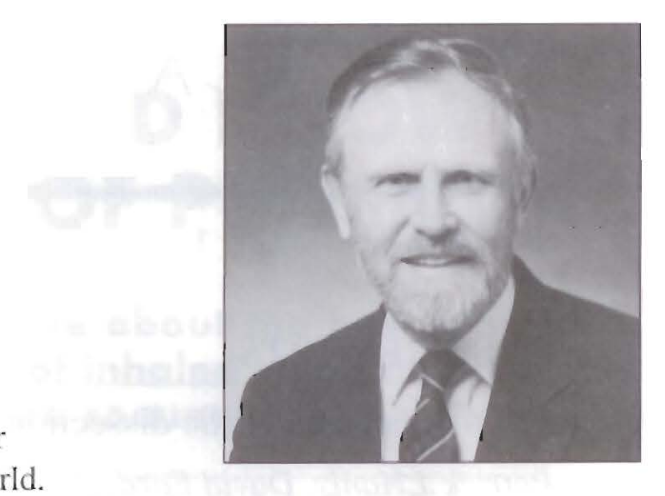
I can think of at least a dozen physicians who by their journeys have made me feel totally lacking in imagination and the spirit of adventure. Of chest physicians I have worked with, the one who comes to mind most colourfully is Philip Hugh-Jones, who first described ' $J$ ' (for Jamaica) diabetes and later carried out imaginative research into regional ventilation-perfusion relationships. Even more imaginative were his regular expeditions to head-hunting country in the upper reaches of the Amazon and in Bolivia, including one in which he was alone for several weeks. In spite of our bets to the contrary, he always made it back, complete with bush babies and poison dart blowpipes that effectively got your attention. if you happened to be dozing in the back row of the lecture theatre. This example is, I admit, a little extreme, but there are many other examples of physicians who have endured hardship and discomfort in following their bliss to remote parts of the world.

Among these must surely be listed Noe Zamel, whose Christie Memorial Lecture appears in the first issue of our second volume (p 18). The thought that the island of Tristan da Cunha might be the place to establish a genetic basis for asthma is an cxample of Medawar's principle that creative imagination is a prime requirement for successful science. It needed more than imagination to carry out this study, however, and it needs a reading between the lines of Noe Zamel's typically understated account to gain an appreciation of the commitment and dedication that he and Pat McClean showed in completing it so successfully. Of the island's population of $3(1)$, complete data were obtained in $282(94 \%)$. We await the results with considerable interest, bearing in mind the recent discovery of the cystic fibrosis gene at the Research Institute of The Hospital for Sick Children in Toronto.

Medawar's view was that "Scientific reasoning is an exploratory dialogue that can always be resolved into two voices or two episodes of thought, imaginative and critical, which alternate and interact". The imagination and exploration have taken place; the critical examination of the hypothesis is to come, but whether it is supported or refuted, there can be no doubt that the effort will have been worthwhile. Darwin would certainly have approved, even though he passed up the chance to visit Tristan da Cunha on the last leg of his five-year voyage on the Beagle. His secrets for success - "a love of science, unbounded patience in long reflecting over any subject, industry in observing and collecting facts, and a fair share of invention as well as of common sense". We maly find them all in Dr Zamel's story. 


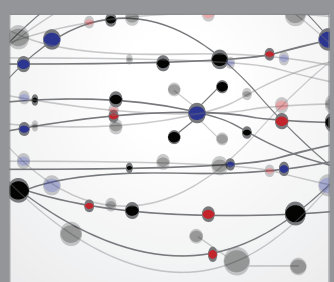

The Scientific World Journal
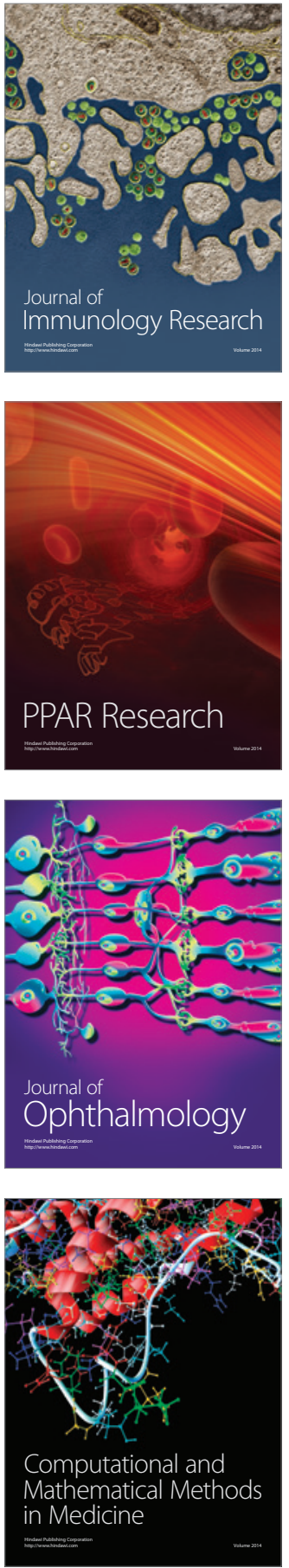

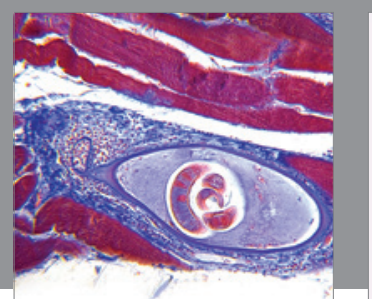

Gastroenterology Research and Practice

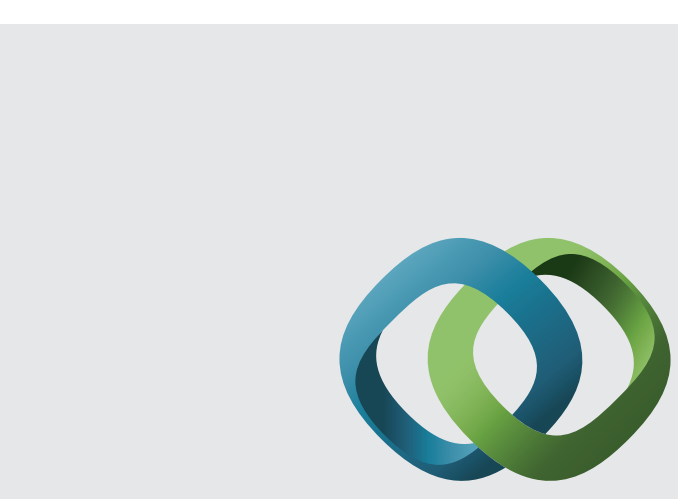

\section{Hindawi}

Submit your manuscripts at

http://www.hindawi.com
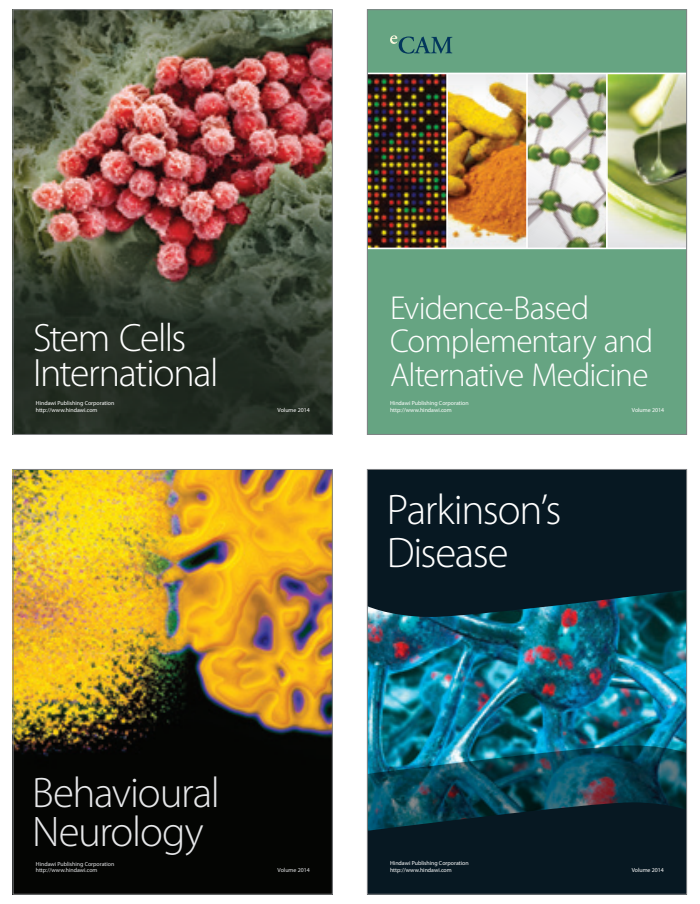
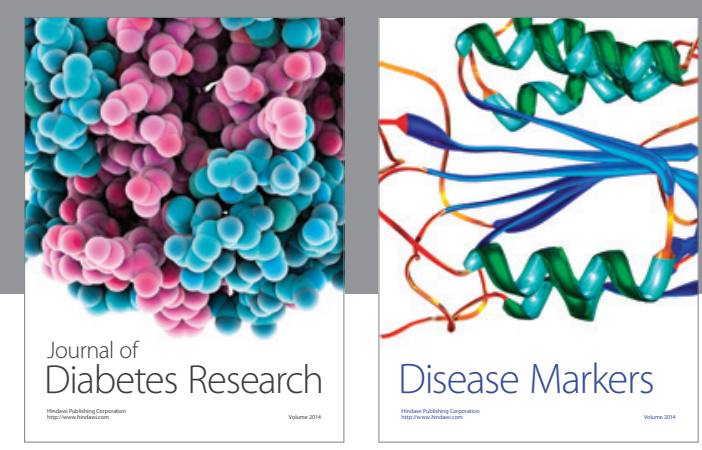

Disease Markers
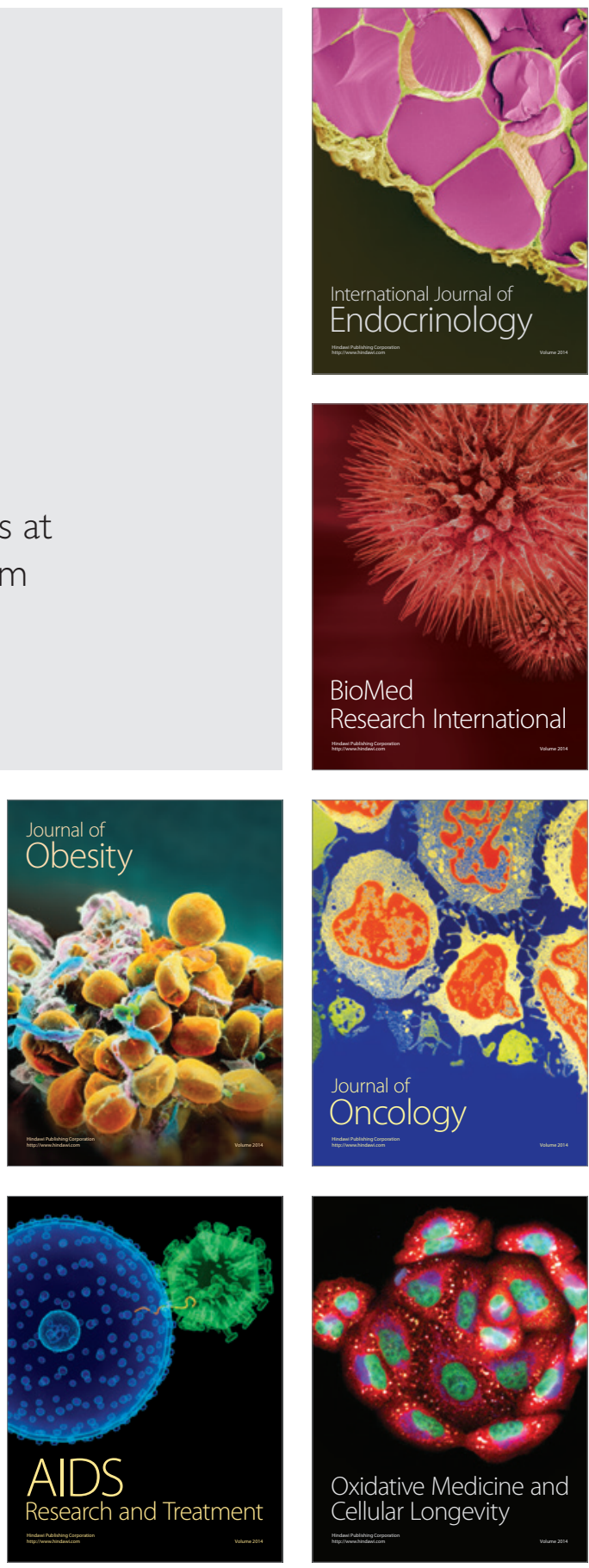